\title{
Effect of Periodontal Treatment on Tooth Mobility*
}

\author{
G. J. Kerry, † E. C. Morrison, † S. P. Ramfjord, † R. W. Hill, † R. G. \\ Caffesse, $\uparrow$ R. R. Nissle $\nmid$ and E. A. Appleberry§
}

Accepted for publication 22 March 1982

\begin{abstract}
ThE PURPOSE of this study was to compare tooth mobility at different time periods during periodontal treatment and to relate changes in mobility to each method of treatment. Ninetythree patients (2421 teeth) with moderate to severe periodontitis were scored: (1) at initial examination, (2) 1 month following scaling, root planing, instruction in oral hygiene and preliminary occlusal adjustment, (3) 1 month after treatment with pocket elimination or reduction, curettage, modified Widman flap or scaling and root planing by the periodontist, and (4) 1 and 2 years following completed periodontal treatment. After initial nonsurgical treatment there was a significant decrease in tooth mobility. Tooth mobility increased temporarily after pocket reduction surgery but was not altered following curettage, modified Widman flap or scaling and root planing. Two years post-treatment there was a trend toward further decrease in tooth mobility with professional tooth cleaning every 3 months.
\end{abstract}

The significance of increased tooth mobility in the etiology and treatment of periodontal disease is controversial. ${ }^{1}$ However, decrease in mobility is generally considered to be a desirable outcome of periodontal therapy, while increasing mobility a year or more after the treatment has been suggested to indicate a need for further dental therapy. ${ }^{2}$ Thus in selection of a modality for periodontal treatment, a favorable mobility response is one of several considerations. Furthermore, mastication on firm teeth is more comfortable than biting on mobile teeth.

A reduction in hypermobility after scaling and establishing good oral hygiene has been reported in several studies, ${ }^{3,4}$ while occlusal adjustment may further decrease the mobility. ${ }^{4,5}$ Studies have included patients with or without occlusal adjustment in addition to the scaling and hygienic therapy. Considerable reduction in mobility along with good results of the periodontal therapy have been seen with or without occlusal adjustment. ${ }^{2,6,7}$ Furthermore, increased mobility after treatment does not seem to influence maintenance of the attachment for teeth as long as the oral hygiene is good and the mobility is not increasing. ${ }^{2}$

\footnotetext{
* This study was supported by Grant No. DE 02731.

$\dagger$ The University of Michigan School of Dentistry, Department of Periodontics, Ann Arbor, MI 48109.

† Present address: 302 Davidson Bldg., Bay City, MI 48706. Formerly Department of Periodontics, The University of Michigan School of Dentistry, Ann Arbor, MI 48109.

$\S$ Present address: 12947 Northline, Southgate, MI 48195 . Formerly Department of Periodontics, The University of Michigan School of Dentistry, Ann Arbor, MI 48109.
}

It appears from previous reports that subgingival curettage or gingivectomy in addition to scaling and occlusal adjustment ${ }^{8}$ may or may not have measurable effect on tooth mobility. ${ }^{9,10}$ Mobility will increase significantly after pocket elimination surgery including bone surgery, ${ }^{11}$ but will return to the presurgical level 1 year after the surgery.

It is not known if the modified Widman ${ }^{12}$ flap surgery which includes incision of the supracrestal fibers has any effect on clinical tooth mobility, and since the same clinical procedures may vary from institution to institution, data from a Michigan study relating changes in clinical mobility to treatment modalities and time are reported.

\section{MATERIALS AND METHODS}

Data for the present study were obtained as part of a previously reported longitudinal investigation comparing results of various modalities of periodontal treatment. ${ }^{13,14}$

Ninety-three patients (2421 teeth) with moderate to severe periodontitis had initial mobility scoring, then a second scoring 1 month following scaling, root planing, instruction in oral hygiene, and occlusal adjustment. A third scoring was done 1 month after completion of the periodontal treatment, a fourth recording in 1 year and a fifth 2 years after completion of the treatment. The patients were on a 3 months recall prophylaxis schedule during the entire study.

Tooth mobility was scored on the basis of the following criteria: ${ }^{15}$

M0: Physiologic mobility, firm tooth 
M1: Slightly increased mobility

M2: Definite to considerable increase in mobility, but not impaired function

M3: Extensive mobility, a "loose" tooth which may be uncomfortable in function.

The periodontal treatment after the initial hygienic phase including occlusal adjustment, was randomized so that each quadrant of the patient's dentition was given either (1) pocket elimination, (2) subgingival curettage, (3) modified Widman flap surgery, and (4) scaling and root planing by a periodontist.

\section{STATISTICAL ANALYSIS}

The Wilcoxon signed rank test ${ }^{16}$ was used for statistical analyses. The pair of measurements for each subject represented the proportions of teeth in each mobility index category at baseline, and 1 month after the hygienic phase, 1 month after the completion of periodontal therapy and 1 and 2 years following completed periodontal treatment. Proportions were derived from twoway contingency tables for categorical variables. The statistic tests the null hypothesis that the distribution of the differences between two proportions in a particular index category between two intervals in time is symmetric about zero. The null hypothesis was rejected at the 0.05 level.

Because of the small number of teeth with extreme mobility (M3) statistical tests were not applicable and therefore these seven teeth were not included in this analysis.

Six patients were selected from among persons accepted for the study for calibration tests. Each patient was scored three times for mobility. Two-way analysis of variance was performed on the six test teeth to determine intraexaminer error. The variation within the examiner for single measurements was 0.03 .

\section{RESULTS}

A significant increase in the proportion of teeth with zero mobility was observed 1 month following completion of the nonsurgical hygienic phase (See Table I). This table illustrates an increase in the proportion of firm teeth after the hygienic phase (initial scaling, root planing and occlusal adjustment).

Results at the different time periods for teeth without mobility are summarized in Table I, the first column. When the results at 1 month post pocket elimination for teeth without mobility are related to the mobility status at the end of the hygienic phase there was a significant decrease $(P<0.05)$ in the proportion of firm teeth in quadrants treated. There was no significant change in the proportion of firm teeth in quadrants treated with curettage, modified Widman flap or scaling and root planing at 1 month post-treatment. After 1 year there were no significant differences in the proportions of firm teeth in the treatment categories of pocket reduction, curettage or modified Widman flap. There was a significant increase $(P<0.05)$ in the proportion of firm teeth which had only been scaled and root planed when compared to ratings following the hygienic phase. Two years after completed periodontal treatment there were no significant differences in the proportions of firm teeth in treatment categories of pocket reduction, modified Widman flap or scaling and root planing. There was an increase $(P<0.05)$ in the proportion of firm teeth 2 years post-curettage.

A summary of results at the different time periods for teeth with slightly increased mobility may be seen in Table I, the second column. There were no significant differences at 1 month post-treatment in the proportions of teeth with slightly increased mobility (M1) in teeth treated with pocket reduction, curettage, modified Widman flap or scaling and root planing when compared to observations following hygienic phase. At 1 year posttreatment there also were no significant differences in the proportions of teeth treated with pocket reduction, curettage, or modified Widman flap. At 1 year there was a decrease $(P<0.05)$ in the proportions of slightly mobile teeth in quadrants treated with scaling and root planing. After 2 years there was a tendency for mobility to decrease in teeth treated with any of the four treatment modalities.

A total compilation of the results for teeth with moderately increased mobility is depicted in the Table I column on the right. When the results at 1 month posttreatment for teeth with moderately increased mobility are related to the mobility status at the end of the hygienic phase there was a significant increase $(P<0.05)$ in the proportions of teeth with moderate mobility in quadrants treated with pocket reduction. There were no significant changes in the proportion of teeth with moderate mobility in quadrants treated with curettage, modified Widman flap or scaling and root planing 1 month post-treatment. One year following completed periodontal treatment there were no significant differences in the proportions of teeth with moderate mobility in all four treatment categories. Two years post-treatment there was a significant decrease in the proportion of teeth with moderate mobility in quadrants treated with curettage or modified Widman flap. In the control quadrants which had scaling and root planing and in quadrants treated with pocket reduction, no significant differences were noted.

\section{DISCUSSION}

The clinical scoring of tooth mobility used in this study is a modification of the method Miller ${ }^{17}$ proposed in 1938. Horizontal dislocation of teeth for evaluation of mobility is used commonly in clinical practice although it does not have the objectivity of the more sophisticated but also more cumbersome mechanical devices which are needed for physiologic and pathologic studies where minute changes may be of essential significance. ${ }^{18,19}$ It 
Table I

Mobility

\begin{tabular}{|c|c|c|c|c|c|}
\hline \multicolumn{2}{|c|}{ Pocket Elimination $(n=606)$} & \multirow{2}{*}{ Mobility Class 0} & \multicolumn{2}{|c|}{ Mobility Class I } & \multirow{2}{*}{$\begin{array}{l}\text { Mobility Class } \square \\
\% \\
9.1 \%\end{array}$} \\
\hline Baseline & $\begin{array}{c}\% \\
38.6\end{array}$ & & $\begin{array}{c}\% \\
52.3\end{array}$ & ২৮০ & \\
\hline Hygienic Phase & 46.4 & \% & 49.5 & +ि. & $4.17 *$ \\
\hline One Month Post & 39.8 & , & 52.9 & & $7.1 \% * *$ \\
\hline One Year Post & 45.7 & , , & 48.8 & & $5.3 \bigcirc$ \\
\hline Two Year Post & 49.6 & 1. & 46.7 & 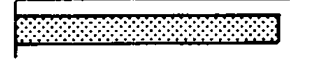 & 3.77 \\
\hline \multicolumn{6}{|l|}{ Curettage $(n=607)$} \\
\hline Boseline & 42.8 & 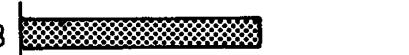 & 47.6 & & 9.6 \\
\hline Hygienic Phase & 48.4 & + & 46.0 & & $5.5 *$ \\
\hline One Month Post & 49.5 & & 46.9 & & 3.6 \\
\hline One Year Post & 52.2 & & 43.0 & & 4.8 网 \\
\hline Two Year Post & 57.1 & 网 & 40.7 & & $2.1 * *$ \\
\hline \multicolumn{6}{|c|}{ Widman Flop $(n=595)$} \\
\hline Baseline & 39.3 & ঋю & 52.3 & & 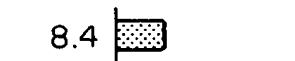 \\
\hline Hygienic Phase & 48.3 & $\%$ & 45.3 & \%०* & 6.43 \\
\hline One Month Post & 44.6 & ,, , & 49.0 & బै & 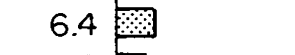 \\
\hline One Year Post & 46.7 & +ా+ా & 48.0 & & 5.32 \\
\hline Two Year Post & 54.8 & ?. & 41.2 & . & 4.0 羿** \\
\hline \multicolumn{6}{|l|}{ Scoling $(n=613)$} \\
\hline Baseline & 40.9 & & 50.4 & & $8.6 ख$ \\
\hline Hygienic Phose & 47.0 & & 47.2 & & $5.8 \otimes$ \\
\hline One Month Post & 49.9 & & 45.8 & & $4.3 \otimes$ \\
\hline One Year Post & 53.0 & ** & 42.1 & \& & 4.9 网 \\
\hline Two Year Post & 53.7 & & 42.4 & & 3.8 \\
\hline
\end{tabular}

appears that clinical methods as used in the present study or similar modifications of the Miller method are fairly reproducible with well calibrated examiners. ${ }^{20}$ This was also indicated by our calibration results.

The present study did not provide an answer to the controversy ${ }^{21,22}$ over the specific role of reduction of inflammation compared with adjustment of occlusion in the reduction of tooth mobility, but it confirmed previous reports of a significant reduction in the number of mobile teeth after initial treatment including occlusal adjustment. The most interesting finding was that the modified Widman flap surgery apparently did not affect tooth mobility; neither did the most "conservative" modality of periodontal surgery, subgingival curettage. Thus whether or not the supracrestal fibers were cut seemingly did not have any effect on the tooth mobility 1 month after the surgery.

That resective periodontal surgery including bone surgery may lead to a temporary increase in tooth mobility has been reported previously ${ }^{11}$ and was confirmed in the present study. The fact that the mobility returned to the presurgical level 1 year postoperatively also supported previous suggestions ${ }^{5,11}$ that it is not the reduction height of the bone level but rather the responses to the surgical trauma that increases the mobility postoperatively. Obviously, this type of surgery has a more profound effect on the deeper periodontium than the laying of a mucoperiosteal flap as in the modified Widman flap surgery.

The slight but gradual decrease in mobility from year 1 to year 2 after the initial treatment may be a manifestation of a slow reorganization of the periodontal supporting structures under good maintenance care. The specific structural and biological phenomena responsible for these changes are not known.

It was also interesting to note that, as reported by Rateitschak $^{8}$ in 1963 , teeth with higher initial mobility values had a greater tendency to improve (get lower mobility) than teeth with initially low mobility values. He also found a gradual, slight decrease in mobility over 2 to 3 years using a mechanical measuring device. 


\section{CONCLUSIONS}

1. Abnormal mobility decreased following the hygienic phase of periodontal treatment (scaling, root planing, polishing, oral hygiene instruction and occlusal adjustment).

2. Tooth mobility was not significantly altered by posthygienic phase, scaling, subgingival curettage or modified Widman flap surgery.

3. Tooth mobility was increased 1 month after pocket elimination surgery, but returned to the presurgical level 1 year later.

4. There was a gradual slight decrease in tooth mobility over 2 years of maintenance care regardless of modality of treatment.

\section{REFERENCES}

1. Ramfjord, S. P., and Ash, M. M., Jr.: Significance of occlusion in the etiology and treatment of early, moderate and advanced periodontitis. J Periodontol 52: 511, 1981.

2. Lindhe, J., and Nyman, S.: The role of occlusion in periodontal disease and the biological rationale for splinting in treatment of periodontitis. Oral Sci Rev 10: 11, 1977.

3. Fehr, C., and Mühlemann, H. R.: Objective Erfassung der Wirkung einer internen Parodontal Therapie ("Biostimulin"). Parodontologie 4: 152, 1956.

4. Wüst, B. P., Rateitschak, K. H., and Mühlemann, H. R.: Der Einfluss der lokalen parodontal Behandlung auf die Zahnlocherung und der Entzündungsgrad des Zahnfleisches. Helv Odontol Acta 4: 58, 1960.

5. Kegel, W., Selipsky, H., and Phillips, C.: The effect of splinting on tooth mobility. I. During initial therapy. J Clin Periodontol. 6: 45, 1979.

6. Lindhe, J., and Nyman, S.: The effect of plaque control and surgical pocket elimination on the establishment and maintenance of periodontal health. A longitudinal study of periodontal therapy in cases of advanced disease. J Clin Periodontol 2: 67, 1975.
7. Rosling, B., Nyman, S., and Lindhe, J.: The effect of systematic plaque control on bone regeneration in infrabony pockets. $J$ Clin Periodontol 3: 38, 1976.

8. Rateitschak, K. H.: The therapeutic effect of local treatment on periodontal disease assessed upon evaluation of different diagnostic criteria. I. Changes in tooth mobility. J Periodontol 34: 540, 1963.

9. Forsberg, A., and Haaglund, G.: Mobility of the teeth as a check of periodontal therapy. Acta Odontol Scand 15: 305, 1958.

10. Burch, J. G., Conroy, C. W., and Ferris, R. T.: Tooth mobility following gingivectomy. A study of gingival support of the teeth. Periodontics 6: 90, 1968.

11. Selipsky, H.: Osseous surgery. How much need we compromise? Dent Clin N Am 20: 79, 1976.

12. Ramfjord, S. P., and Nissle, R. R.: The modified Widman flap. $J$ Periodontol 45: 601, 1974.

13. Morrison, E. C., Ramfjord, S. P., and Hill, R. W.: Short term effects of initial, nonsurgical periodontal treatment (hygienic phase). $J$ Clin Periodontol 7: 199, 1980.

14. Hill, R. W. et al.: Four types of periodontal treatment compared over four years. $J$ Periodontol 52: 655, 1981.

15. Ramfjord, S. P.: Periodontal disease index (PDI). J Periodontol 38: 602,1967

16. Hollander, M., and Wolfe, D.: Nonparametric Statistical Methods. New York, John Wiley Co., 1973.

17. Miller, S. C.: Textbook of Periodontia, ed 1. Philadelphia, Blakiston, 1938.

18. Mühlemann, H. R.: Tooth mobility. I. The measuring method. Initial and secondary tooth mobility. $J$ Periodontol 25: 22, 1954.

19. O'Leary, T. J.: Indices for measurement of tooth mobility in clinical studies. J Periodont Res (suppl.) 14: 94, 1974.

20. Laster, R., Lauderback, K. W., and Stoller, N. H.: An evaluation of clinical tooth mobility measurements. J Periodontol 46: 603, 1975.

21. Mühlemann, H. R.: Tooth mobility. A review of clinical aspects and research findings. $J$ Periodontol 38: 686, 1967

22. Son, S., Holz, P., and Mühlemann, H. R.: The effect of marginal gingivitis on tooth mobility. Helv Odontol Acta 15: 103, 1971.

Send reprint requests to: Dr. Sigurd P. Ramfjord, University of Michigan, School of Dentistry, Ann Arbor, MI 48109.

\section{Announcements}

\section{LONG ISLAND JEWISH-HILLSIDE MEDICAL CENTER}

The Long Island Jewish-Hillside Medical Center annouces a 4-Day Dental Training Program in Developmental Disabilities and Related Disorders.

DATE: $\quad$ November $14-17,1982$

AT: $\quad$ Long Island Jewish-Hillside Medical Center, New Hyde Park, New York 11042

Sponsor: The Department of Dentistry, Long Island Jewish-Hillside Medical Center and the Health Sciences Center, State University of New York at Stony Brook

TuITION: $\quad \$ 300 ; \$ 150$ for residents, dental auxiliaries and students includes luncheons and coffee breaks; Registration limited

Chairman: Saul Kamen, D.D.S.

This 4-day seminar will emphasize the clinical management of patients with a side range of physical and mental disabilities. It will explore, in depth, the nature of neurological and psychosocial impairment, as well as techniques for the dental management of patients with concomitant behavioral disorders. It will include demonstrations in the clinics and operating rooms, and a field trip to an outstanding day center for the education and vocational rehabilitation of the mentally retarded. The curriculum is designed to meet the needs of general practitioners, specialists, academicians, institutional dentists and dental hygienists.

For more information contact: Ann J. Boehme, Continuing Education Coordinator, Long Island Jewish-Hillside Medical Center, New Hyde Park, NY 11042. (212) 470-2114.

\section{THE UNIVERSITY OF PENNSYLVANIA SCHOOL OF DENTAL MEDICINE}

The University of Pennsylvania School of Dental Medicine announces the following continuing education course:

Title: Hawley Bite Plane and Night Guard Therapy

DATE: Saturday, November 20, 1982

Faculty: Francis S. Matarazzo, D.D.S., Clinical Associate Professor of FFMS and Clinical Director of Graduate Periodontal Prosthesis Program, University of Pennsylvania

The course is designed for practitioners and specialists alike and will include a demonstration of the insertion and adjustment of a Hawley and maxillary night guard. Main topics of interest are: Design and fabrication of the Hawley Bite Plane and maxillary night guard; indications and contraindications for the appliances; relining technique when indicated and evaluation effects of the appliances. 